\title{
Racial Climate and Mental Health Service Utilization among Black College Students at Diverse Institutions
}

Seanna Leath* is an assistant professor of psychology at the University of Virginia.

Martinque Jones ${ }^{\dagger}$ is an assistant professor of psychology at the University of North Texas.

Leath, S., \& Jones, M. (2021). Racial climate and mental health service utilization among Black college students at diverse institutions. Currents, (2)1.

Keywords: Black college students, mental health services, wellness, minority heath

Black college students contend with culturally specific concerns (e.g., ism's, discrimination, and marginalization), which can undermine their mental health and academic performance (Bernard et al., 2017). Yet they are less likely to receive support from mental health professionals in college counseling centers (Anderson, 2018). The reasons for service underutilization among Black college students are wide-ranging and include mental health stigma, cultural mistrust, and the underrepresentation of Black counseling professionals (Cabral \& Smith, 2011;

*sl4xz@virginia.edu

†martinque.jones@unt.edu 
Center for Collegiate Mental Health, 2016; Masuda et al., 2012). Although institutions have the potential to minimize the aforesaid barriers to service utilization, less research has specifically examined how institutional climate inhibits or supports Black students' utilization of mental health services and the subsequent impact on their overall college adjustment.

We define institutional climate broadly to include students' perceptions of academic and social norms and institutional values, as well as faculty-student relationships, diversity in the faculty and student body, and student support services. In relation to mental health, institutional climate includes students' perceptions of mental health stigma on campus and knowledge of services, as well as the perceived support they receive from peers, faculty, and student organizations. Black students who have a more negative perception of their institutional climate may be less inclined to pursue mental health services when in need because they perceive the institution to be ill equipped to address their culturally specific concerns (Harris, 2012), which may, in turn, contribute to more chronic forms of stress. Alternately, Black students who have more positive perceptions of their institutional climate may be more likely to seek mental health support when needed because they view their institution as supportive and inclusive and, in turn, reap the psychosocial and academic benefits of the support rendered.

Yet current understandings of the mental health processes among Black college students is limited. First, few studies consider wellness among Black students from a holistic framework that considers both psychological and academic factors (for similar work with other student samples, see Cuevas et al., 2017; Morgan et al., 2016). Second, many studies fail to capture the intersectionality of Black students' lived experiences, despite evidence that Black students have unique experiences related to their multidimensional social identities (e.g., ethnicity, gender, and sexuality; Harper \& Nichols, 2008; Means \& Jaeger, 2015). Finally, there is little empirical evidence that considers Black student wellness across diverse institutions. Thus, our project had three primary goals: (1) to examine the association between Black 
student's perceptions of their institutional climate, self-reported rates of mental health service utilization, and adjustment; (2) to give voice to Black students within the current political climate; and (3) to provide universities with "better practice" recommendations based on our findings.

\section{Method and Results}

Our project integrated secondary data from a multi-institutional survey and primary qualitative data from Black students at two unique institutions. First, we utilized existing nationally representative survey data from the Healthy Minds Study (HMS), which included responses from over 2,009 Black college students at 15 racially diverse institutions across the United States. The HMS includes a range of demographic items as well as measures that assess students' perceptions of institutional climate (e.g., faculty/student relationships, experiences of discrimination, diversity/inclusion climate, and mental health climate). In relation to mental health, we used indices of overall health, knowledge and attitudes about mental health services, help-seeking intentions, and use of formal and informal supports, as well as academic outcomes like GPA, sense of belonging, and persistence. Second, we conducted one-on-one semistructured interviews with 48 Black college students at a predominantly white institution (PWI) and a minority-serving institution (MSI) to further explore similarities and differences in the perceived institutional barriers and supports to mental health service utilization and wellness.

\section{Main Findings}

For the purposes of this insight paper, we aggregated results from three forthcoming papers that offer insight into Black students' perceptions of institutional climate and mental health in unique ways. 


\section{Black Students' Perceptions of Institutional Diversity Climate}

Based on the quantitative data, Black students who perceived the campus as more welcoming to first-generation and immigrant students reported higher positive mental health. Black students who perceived that the campus was more welcoming to racial and ethnic minority students indicated lower levels of anxiety. These findings underscore the need for more research on individual-level differences in Black students' mental health processes and draw attention to the ways in which students from diverse backgrounds value a welcoming and supportive environment for all student communities.

\section{Black Students' Perceptions of Racial Hate Crimes on Campus}

Based on qualitative data with Black students from the PWI, August 11 and 12, 2017 (i.e., two days of demonstrations by white supremacists and neo-Nazis, as well as counter protesters from Black Lives Matter and antifa), spotlighted UVA's racial conflict and monuments to white supremacy. The students described how the events fundamentally shaped their understanding of the university racial climate, as well as the lack of institutional care for Black students. This event influenced many of the currently enrolled Black students to rally around the incoming first year students and encouraged them to draw on the resistance of the Black college community writ large to call out institutional inaction during and after the rallies.

\section{Black College Students' Perceptions of Race in Counseling}

Based on qualitative data with students at both institutions, inadequate representation of Black counselors was a barrier to therapy (e.g., Jamal: "I feel like having a Black therapist will allow ... [me] to be more comfortable with talking. But that goes back to the underrepresented and limited Black faces in those roles."). Additional barriers to counseling noted by Black college students included 
(a) advertising/promotion of services, (b) long wait lists/limited availability of services, and (c) session costs. Our findings mirror extant studies demonstrating that people of color are, on occasion, met with counselors who are unable to engage them in deep and meaningful therapeutic work, in part because of counselor biases toward the client's cultural group.

\section{Recommendations}

\section{With Regards to Improving Institutional Climate}

- Administrators must recognize how institutional histories of racial exclusion and the enduring reality of white privilege harm the social and psychological processes of Black undergraduate students. This should include finding new tools and strategies for supporting and promoting diverse student bodies in contemporary higher education contexts that account for student's intersectional identities.

- If PWls are to find a way forward in antiracist efforts, administrative leaders must unequivocally remove testaments to white supremacy. We have seen recent efforts on some campuses, including UVA, such as changing building names and defunding campus police officers and other carceral agents who represent a threat to the safety of Black students.

- Centering Black student voices, needs, and desires in university decision-making processes may lend itself to the radical shift in academic and social structures needed to dismantle institutional whiteness.

- Our findings also suggest that institutions need to do a better job of investing resources in local communities and grassroots efforts. This investment would benefit all students in their understanding of how racism manifests in spaces within and beyond academe and, equally important, would demonstrate a commitment to reconcile 
the ongoing racial trauma and tensions between institutions and local communities borne of white supremacy and colonialism.

\section{With Regards to Improving Black Students' Mental Health and Wellness}

- Black students perceive Black clinicians as best suited for their counseling needs, but they also suggested that other counselors, particularly those who are committed to multicultural humility, may be similarly equipped to support them in addressing their concerns. Thus, we recommend that education administrators allocate funds to sustain college counseling centers and specifically fund the hiring of diverse counseling staff. Currently, many institutions allocate miniscule amounts of funding to college counseling centers (Bishop, 2010), which undermine hiring and retention of diverse counseling staff, as well as the extent to which centers can offer curated services for diverse student groups.

- In addition, consistent with the recommendations posed by the Association for Multicultural Counseling \& Development (Chu et al., 2016), we contend that non-Black and Black counselors alike benefit from continued awareness and training on how their biases influence their interactions with those who are culturally different. Perceived lack of understanding from their non-Black counselor was a barrier to treatment among students, which may be more readily addressed by encouraging clinicians to be privy to societal issues (e.g., racial unrest, protest, immigration laws) impacting Black students' psyche.

- Finally, counseling centers can address some of the other barriers to mental health service utilization by (a) allowing students to indicate preferred counselor demographics on their intake form and try to honor their preferences, (b) advertising services in a way that is appealing to students of diverse cultural backgrounds (Jones \& Pritchett-Johnson, 2018), (c) reducing wait time/broadening the availability of services, and (d) ensuring session costs are free or affordable for students. 


\section{Biographies}

Dr. Seanna Leath's research focuses on addressing how race and gender identity beliefs support psychological resilience among Black girls and exploring the influence of discrimination and stigma on a variety of outcomes among Black girls and women.

Dr. Martinque Jones's research centers on applying an intersectional framework to the study of Black women's identity, mental health, and counseling processes.

\section{References}

Anderson, M. (2018). Barriers to the utilization of mental health services on college campuses by African American students. McNair Scholars Research Journal, 11(1), 1-12.

Bernard, D., Lige, Q., Willis, H., Sosoo, E., \& Neblett, E. (2017). Imposter phenomenon and mental health: The influence of racial discrimination and gender. Journal of Counseling Psychology, 64(2), 155-166. https://doi. org/10.1037/cou0000197

Bishop, J. B. (2010) The counseling center: An undervalued resource in recruitment, retention, and risk management. Journal of College Student Psychotherapy, 24(4), 248-260. https://doi.org/10.1080/87568225.2010. 509219

Cabral, R. R., \& Smith, T. B. (2011). Racial/ethnic matching of clients and therapists in mental health services: A meta-analytic review of preferences, perceptions, and outcomes. Journal of Counseling Psychology, 58(4), 537-554. https://doi.org/10.1037/a0025266

Center for Collegiate Mental Health. (2016, January). 2015 annual report (Publication No. STA 15-108). State College, PA: Pennsylvania State University.

Chu, J., Leino, A., Pflum, S., \& Sue, S. (2016). A model for the theoretical basis of cultural competency to guide psychotherapy. Professional Psychology: Research and Practice, 47(1), 18-29. https://doi.org/10.1037/pro0000055

Cuevas, A., Shreiner, L., Young, K., \& Bloom, J. (2017). Honors student thriving: A model of academic, psychological, and social wellbeing. Journal of the National Collegiate Honors Council, 18(2), 79-119.

Harper, S., \& Nichols, A. (2008). Are they not all the same? Racial heterogeneity among Black male undergraduates. Journal of College Student Development, 49(3), 199-214. https://doi.org/10.1353/csd.0.0003 
Harris, A. L. (2012). Barriers to group psychotherapy for African-American college students (Doctoral dissertation). Retrieved from http://corescholar. libraries.wright.edu/etd_all/669/

Jones, M. K., \& Pritchett-Johnson, B. (2018). "Invincible Black Women": Group therapy for Black college women. Journal for Specialists in Group Work, 43(4), 349-375. https://doi.org/10.1080/01933922.2018.1484536

Masuda, A., Anderson, P. L., \& Edmonds, J. (2012). Help-seeking attitudes, mental health stigma, and self-concealment among African American college students. Journal of Black Studies, 43(7), 773-786. https://doi. org/10.1177/0021934712445806

Means, D. R., \& Jaeger, A. J. (2015). Spiritual borderlands: A Black gay male college student's spiritual journey. Journal of Student Affairs Research and Practice, 52(1), 11-23. https://doi.org/10.1080/19496591.2015.1009341

Morgan, C., Llamas, J., \& Consoli, A. (2016). What's values got to do with it? Thriving among Mexican American college students. Journal of Multicultural Counseling \& Development, 44(1), 49-64. https://doi.org/10.1002/ jmcd.12036 